\title{
Uma visão arquivística sobre os documentos fotográficos referentes ao decanato de ensino de graduação presentes no acervo do Centro de Documentação da Universidade de Brasília*
}

\author{
André Porto Ancona Lopez \\ Doutor em história e especialista em organização de arquivos \\ pela Universidade de São Paulo (USP). Professor do Curso de \\ Arquivologia da Universidade de Brasília (UnB), Departamento de \\ Ciência da Informação e Documentação. Brasília, DF, Brasil. \\ E-mail:apalopez@gmail.com
}

Leandro de Melo Borges

Arquivista pela Universidade de Brasília (UnB). Departamento de Ciência da Informação e Documentação. Brasília, DF, Brasil. E-mail: demeloborges@yahoo.com.br

\author{
An archival view of photographic \\ documents referring to the deanship of \\ teaching and graduation present in the \\ collection of the documentation center of \\ University of Brasilia
}

\begin{abstract}
The Documentation Center of the University of Brasilia (CEDOC-UNB) is a consulting department of the university higher administration. Its formal aim is to collect, preserve and guarantee the access to archival documents produced and accumulated by the offices and faculties of UNB, as well as to historical and cultural goods, which are an instrument for supporting the administration, culture, history and scientific and technological development. This article is limited to the photographs originated from the Deanship of Graduation Teaching (DEG-UNB), existing at CEDOC's collection, analyzing the acceptance of the treatment of that material to the archival theoretical and methodological directions. The system has been notably planned for privileging the image contents in opposition to what is expected from an archive, where the archival context should be the primordial point of organization and description of photographs.
\end{abstract}

\section{Keywords}

Documentation Center of the University of Brasilia (CEDOC-UNB); Deanship of Graduation Teaching of the University of Brasilia (DEG-UNB); Archival description; Archival photographic documents; Archival bond; archival principles.

\section{Palavras-chave}

Centro de Documentação da Universidade de Brasília (Cedoc). Decanato de Ensino de Graduação (DEG). Descrição arquivística. Documentos fotográficos de arquivo. Organicidade arquivística. Princípios arquivísticos. 


\section{INTRODUÇÃO}

Tradicionalmente, a organização de documentos imagéticos tende a valorizar a informação visual, relegando a um segundo plano o contexto de produção do documento. Tal conduta seria justificada pela dificuldade de recomposição dos motivos da produção documental. Os modelos elaborados geralmente partem das informações veiculadas pela imagem como referencial para a classificação e descrição, sem fazer, na verdade, qualquer tentativa de contextualização documental, em termos arquivísticos. Esse tipo de organização traz sério risco de comprometer tanto o valor probatório de documentos de primeira e segunda idades, como o acesso ampliado aos documentos permanentes, caso o documento imagético disponibilizado não seja devidamente contextualizado (cf. LOPEZ, 2003a, 2005).

Autores consagrados também apontam a necessidade da permanência dos dados geracionais da imagem, sob risco de perda de sua autenticidade como registro fotográfico (cf. SMIT, 1996; 1998; PARINET, 1996). Somente com respeito à proveniência* é que toda a dimensão comunicativa da mensagem da fotografia (cf. GOMBRICH, 2000) pode ser exercida (cf. JOLY, 1996). Deste modo, não basta disponibilizar imagens e fotografias para o pesquisador, se estas não estiverem claramente ligadas ao seu vínculo institucional.

Entendemos a recuperação do contexto de produção - relativa a documentos imagéticos ou não - como tarefa indispensável da organização arquivística, capaz de garantir informações fundamentais aos usuários de qualquer documento. Entretanto, esse cenário, no caso de materiais arquivísticos, esbarra em uma questão de ordem conceitual mais ampla: como fazer para conciliar as especificidades impostas pelo documento fotográfico com as exigências internacionais da descrição arquivística?

\footnotetext{
* "Princípio da proveniência: princípio segundo o qual os arquivos originários de uma instituição ou de uma pessoa devem manter sua individualidade, não sendo misturados aos de origem diversa." (Dicionário, 1996, p.61). Ver também: BELLOTTO, 2004.
}

O presente trabalho é resultado de um estudo de imagens na qualidade de documentos arquivísticos, feito a partir das fotografias referentes às atividades do Decanato de Ensino de Graduação da Universidade de Brasília (Deg), constantes do acervo fotográfico do Centro de Documentação (Cedoc). Procura discutir, do ponto de vista do ferramental teórico da arquivologia, a adequação do sistema de recuperação dessas imagens.

Durante a pesquisa, após o aprimoramento de nossa base teórica, mediante leitura dirigida de textos, discussões e visitas técnicas, aplicamos procedimentos arquivísticos de diagnóstico e buscamos analisar o material oriundo do Deg disponível no Cedoc. A análise levou em consideração Cd-rom disponibilizado pelo Cedoc com material referente ao Deg, bem como fichas utilizadas para referenciação e controle do acervo fotográfico, além de entrevistas informais com os funcionários (sempre atenciosos), feitas com a finalidade de obter informações acerca dos procedimentos adotados. Tais informações foram analisadas e comparadas aos princípios da arquivologia e a procedimentos adotados por outras instituições, presentes na literatura especializada. Buscou-se entender como as informações contextuais arquivísticas desse tipo de documento imagético são trabalhadas. O foco do presente estudo é, pois, a análise da fotografia como documento de arquivo e não uma visão geral da instituição em questão*

\section{O CEDOC E SEU ACERVO FOTOGRÁFICO}

Em agosto de 1986, foi criado, provisoriamente, pelo Ato da Reitoria No 345/86, o Centro de Documentação e Arquivo da Universidade de Brasília (Cedaq). Posteriormente, em outubro de 1988, foi constituído como um centro de custos, denominado Centro de Documentação da Universidade de Brasília (Cedoc). É um órgão de assessoramento da Administração Superior da Universidade, que tem por finalidade recolher, preservar e garantir o acesso

* Nesse sentido, as discussões relativas ao diagnóstico de arquivos, como, por exemplo, Cornelsen; Nelli, 2006 e Evans; Ketelaar, 1983, não foram contempladas. 
aos documentos arquivísticos de valor permanente, produzidos e acumulados pelas áreas meio e fim da UnB, bem como aos bens culturais e históricos, constituindo instrumento de apoio à administração, à cultura, à história e ao desenvolvimento científico e tecnológico. Parte desse acervo é composto por documentos audiovisuais. Para os fins deste trabalho, vamos nos ater aos documentos fotográficos.

O Cedoc tem um acervo fotográfico com cerca de 8 mil fotografias, originadas tanto das atividades da assessoria de comunicação quanto de doação de funcionários, professores, alunos e ex-alunos, correspondentes ao período 1961-2006, referentes à criação, construção, reitores, atividades políticas e outros eventos relacionados à UnB. Conta ainda com cerca de 250 fitas de vídeo referentes à campanha presidencial de 1989, além de cartazes que compõem os acervos do Centro Acadêmico de História, do Cine Clube Dois Candangos e do Instituto de Artes. Recentemente - não foi informado exatamente quando - foi doada uma grande quantidade de fotos do arquivo do Campus, jornal laboratório da Faculdade de Comunicação.

Grande parte do acervo já foi digitalizada. As buscas são feitas em uma base de dados montada a partir do software Light Base for Windows (LBW) com o uso de palavras-chave relacionadas às descrições feitas anteriormente pelos funcionários. As informações que alimentam a base de dados, bem como os campos onde se inserem os descritores para as buscas no sistema, são similares às constantes das fichas de descrição dos positivos originais, as quais exemplificamos melhor mais à frente.

À guisa de exemplo, suponhamos que um pesquisador esteja à procura de imagens relacionadas à assinatura do decreto-lei de criação da UnB. Pode-se usar tanto a palavra "lei", quanto o nome de uma das autoridades presentes no evento. Entretanto, na janela onde surge o resultado da busca não é exibida instantaneamente uma reprodução do documento fotográfico, porém uma ficha descritiva, conforme pode ser visto na figura 1. A imagem é armazenada como página da Web e, no ambiente de apresentação, é exibido um link para o documento fotográfico.

Os documentos fotográficos estão acondicionados em camisas de papel neutro, arquivados em mobiliário de metal, havendo conjuntos que ainda não foram objeto do processo que os funcionários chamam de cadastramento. No que tange ao arquivamento* do acervo fotográfico, dentro das escassas possibilidades de recursos - problema, infelizmente, comum a qualquer universidade pública -, tudo tem sido feito da melhor forma. O mesmo não se pode dizer quanto à organização arquivística do acervo. Não existem instrumentos de pesquisa além das fichas, como guias, inventários, índices ou quadros de arranjo. O que seria altamente desejável, já que, segundo Lopez (2002, p.13), os instrumentos de pesquisa "são as ferramentas utilizadas para descrever um arquivo, ou parte dele, tendo a função de orientar a consulta e de determinar com exatidão quais são e onde estão os documentos".

As fichas realizam apenas uma descrição individualizada dos conteúdos da imagem, sem dar uma dimensão mais ampla para a instituição e seu acervo. Os campos das fichas de identificação dos positivos fotográficos são os seguintes:

a) Localização: corresponde ao local onde o documento está armazenado.

b) Data de entrada: data em que chegou o documento ao Cedoc.

c) $\mathrm{N}^{\circ}$ do negativo: usado somente quando existe um negativo fotográfico. Os negativos também são digitalizados para visualização, mas não são disponibilizados para reprodução por faltarem recursos.

\footnotetext{
* Em nossa acepção o termo está relacionado às atividades de acondicionamento físico do acervo, em contraposição ao conjunto de operações lógicas referentes ao tratamento arquivístico, ou tratamento documental. Tal distinção é sustentada pelo Dicionário de terminologia arquivistica (1996): "Arquivamento: conjunto de operações de armazenamento e acondicionamento de documentos." (p.4); e "Tratamento documental: conjunto das atividades de classificação e descrição de documentos." (p.75).
} 


\section{FIGURA 1}

Tela de consulta às fotografias do Cedoc

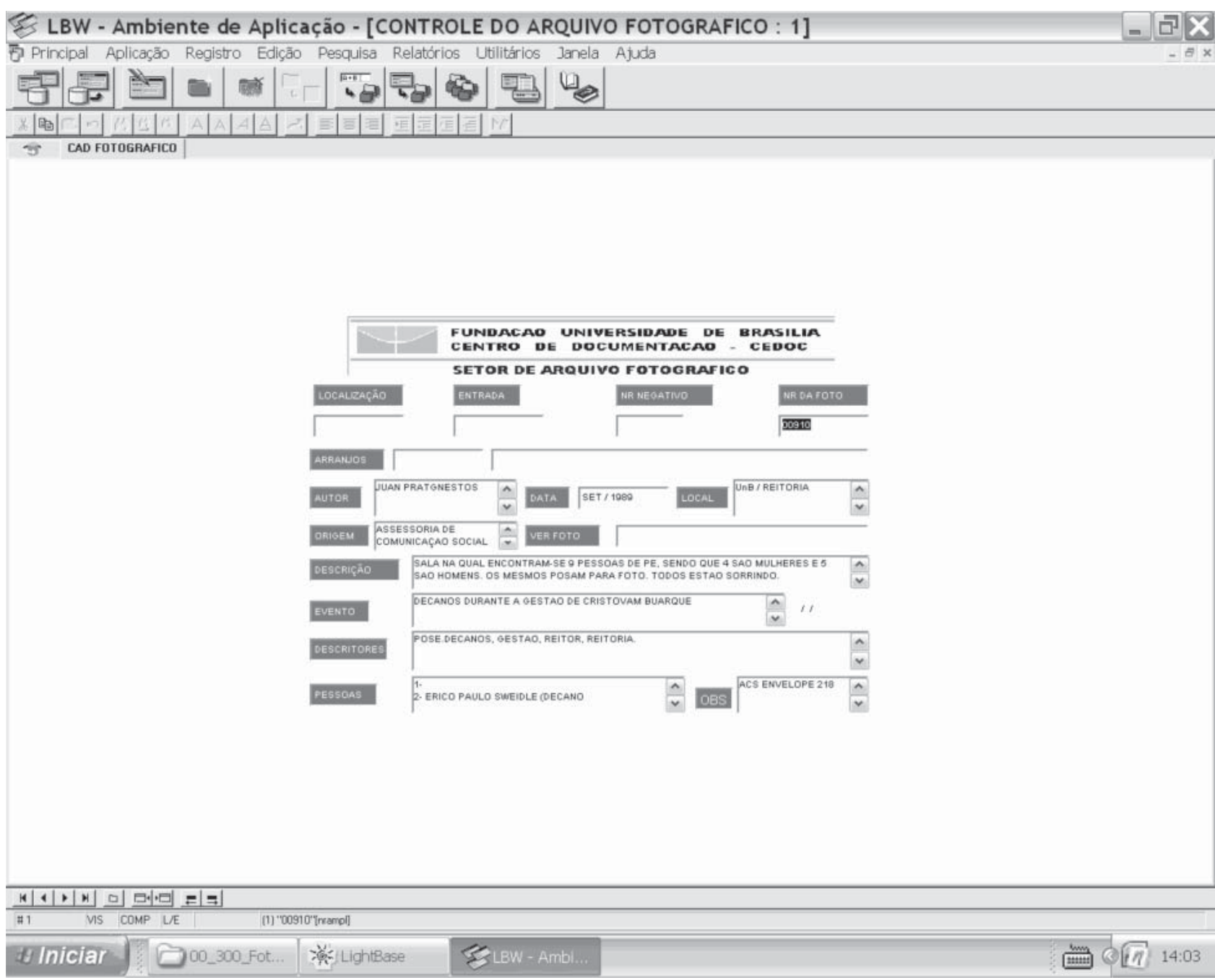

Fonte: Cedoc

d) $\mathrm{N}^{o}$ da foto: numeração sequencial que torna possível a recuperação da fotografia no mobiliário.

e) Palavra-chaves (sic): indexadores que se refiram ao que é possível visualizar na imagem, bem como ao evento registrado.

f) Arranjos (sic): em branco, pois não existe quadro de arranjo ou plano de classificação. Caso seja elaborado, as informações a ele pertinentes deverão ser registradas em tal campo.

g) Código: em branco; numeração relacionada ao quadro de arranjo, quando este for produzido.

h) Autor: o nome do fotógrafo.

Ci. Inf., Brasília, DF, v. 38, n. 3, p.160-176, set./dez., 2009 i) Origem: quem efetuou a doação para o Cedoc.

j) Data: se possível, a data em que foi registrada a imagem por meio da fotografia.

k) Local: onde se deu o evento fotografado.

1) Descrição: o que se vê na fotografia.

m) Eventos (sic): o acontecimento registrado.

n) Pessoas: o nome das pessoas que se conseguiu identificar.

o) Observações: outras informações que forem julgadas relevantes. 
Quando da digitalização do acervo, algumas informações das fichas foram utilizadas para alimentar a base de dados. No ambiente de busca eletrônica, há a inserção de um campo extra para o acesso à cópia digital da imagem. Os demais campos apenas reproduzem os campos da ficha manuscrita, com eventuais modificações quanto à grafia ou a denominação. São eles:

a) Localização: idem campo "a”, acima.

b) Entrada: idem campo "b”, acima.

c) Nr negativo: idem campo "c", acima.

d) $\mathrm{Nr}$ da foto: idem campo "d", acima.

e) Arranjos (sic): engloba os campos "f $\mathrm{f}$ " e "g", acima.

f) Autor: idem campo "h", acima.

g) Data: idem campo “j”, acima.

h) Local: idem campo "k", acima.

i) Origem: idem campo “i”, acima.

j) Ver foto: campo novo; link para a página-web em que foi armazenada a fotografia.

k) Descrição: idem campo "l”, acima.

l) Evento: idem campo “m”, acima.

m) Descritores: idem campo "e", acima, porém com outro nome.

n) Pessoas: idem campo “n”, acima.

o) Obs: idem campo “o”, acima.

A existência desses campos constitui grande facilitador das buscas ao facultar uma seleção mais direcionada. Por exemplo, uma busca feita a partir do campo pessoas pode revelar a existência de mais de um documento fotográfico, no qual determinada pessoa se faça presente, contudo uma nova pesquisa feita a partir do evento pode conferir maior eficácia ao esforço de localizar a imagem desejada.

Como veremos adiante, tais campos, sobretudo em razão da maneira com a qual estão sendo trabalhados, não se mostram eficazes. Para melhorar a eficiência na recuperação documental, seria necessária a ampliação dos campos, de modo a englobar informações referentes à produção arquivística. Haveria ainda a necessidade de estabelecimento de uma denominação mais precisa e, sobretudo, de um manual com definições mais detalhadas quanto ao significado de cada campo, além de instruções exatas quanto à forma de preenchimento, a fim de garantir maior padronização.

A existência de campos destinados à inserção de dados referentes a um futuro plano de classificação (ou quadro de arranjo) não preenchidos chama a atenção. A adoção de procedimentos de descrição arquivística em conjuntos que não tenham sido processados quanto à classificação é um procedimento altamente criticado pela teoria arquivística.

Os documentos fotográficos são ordenados por sequência numérica e têm seu conteúdo visual descrito de acordo com referencial teórico obtido em textos de Marilena Leite Paes (2004). Tal metodologia é, há algum tempo, considerada imprópria pela teoria arquivística, sobretudo por tratar os documentos fotográficos em função de seu conteúdo imagético, ignorando os dados de contexto arquivístico.

Problemas oriundos deste tipo de tratamento foram amplamente discutidos por Lopez (2000; 2008; 2009). Qualquer documento arquivístico isolado de seu contexto de produção (o objetivo ou a finalidade para o qual foi produzido e arquivado) tem sua real compreensão quase impossibilitada. Em tal cenário, as atividades de classificação arquivística e criação de instrumentos de pesquisa - com informações arquivísticas - verificam-se impraticáveis. Se esse quadro se faz presente em acervos com documentos fotográficos, não temos mais um arquivo, porém um banco de imagens meramente ilustrativas.

\footnotetext{
* Para maiores detalhes quanto à articulação entre as atividades de classificação e as de descrição, consultar Lopez 2002b e 2003b.
}

Ci. Inf., Brasília, DF, v. 38, n. 3, p.160-176, set./dez., 2009 
Entende-se que se deva trabalhar com um fundo maior (fundo UnB, por exemplo) e só então fazer uma divisão por unidades. Os acervos de doadores externos - se aplicado o princípio fundamental da arquivologia, a proveniência - devem dar origem a vários outros fundos. Não é o que verificamos na prática. Por exemplo, existe uma divisão (conforme terminologia utilizada pelos funcionários do Cedoc) do Fundo UnB chamada Faculdade de Psicologia e, dentro dela, o Fundo Fred Keller, constituído pela doação externa de documentos produzidos e/ ou acumulados por um dos pioneiros da referida faculdade. Tal prática se configura como um evidente desrespeito aos princípios norteadores da arquivologia e impossibilita atender minimamente aos requisitos exigidos pelo Conselho Internacional de Arquivos para a aplicação da Norma Internacional de Descrição Arquivística (Isad-g) ${ }^{*}$, bem como a Norma Brasileira de Descrição Arquivística (Nobrade) $^{* *}$.

\section{AS FOTOGRAFIAS REFERENTES AO DEG}

O panorama relativo ao Cedoc, apontado acima, foi observado a partir de informações colhidas e do material que nos foi disponibilizado. Dentro de nossos objetivos iniciais, utilizamos como material empírico a busca por registros fotográficos referentes ao Deg, efetuada naquele acervo. Ao indicar os indexadores "DEG" e "Decanato de Ensino de Graduação" no campo "origem" - o qual nos parece ser o mais similar à produção arquivística -, obtivemos retorno nulo. Ao efetuar nova busca, utilizando como palavra-chave o termo "Decanato de Ensino de Graduação", encontramos apenas oito reproduções fotográficas referentes a atividades desenvolvidas, ou retratos de ex-decanos, produzidos pela Assessoria de Comunicação Social da UnB (Acs). Esperávamos poder contribuir efetivamente com as atividades de memória institucional do Deg. Temos, porém, consciência de que o quantitativo, apesar de representar 100\%

\footnotetext{
* A versão original foi publicada por International Council on Archives, 2000. Lopez (2002a) faz um breve histórico da norma.

** Ver BRASIL. Conselho Nacional de Arquivos, 2006.
}

disponibilizado pelo atual sistema de acesso do Cedoc, não é, efetivamente, representativo das atividades desenvolvidas pelo Decanato.

Nas páginas adiante estão reproduzidos (em tamanho reduzido) os mencionados registros e as respectivas fichas descritivas. Em alguns casos, foi acrescentada uma ficha complementar para dar conta da exibição das informações de campos que ficaram truncados na cópia para o presente texto.

Ao analisar a informação disponibilizada pelas fichas, continuamos a não ter informações suficientes sobre as atividades arquivísticas e administrativas que originaram a produção e a guarda arquivística dos documentos fotográficos. Evidencia-se, ainda, a ausência de informações quanto ao arranjo, cujo campo está sem preenchimento em todas as fichas, além de dados mais específicos sobre o suporte, ou seja, a respeito da materialidade do documento. $\mathrm{O}$ conhecimento prévio das atividades da Acs, somado ao fato de ser a referida assessoria a origem dos registros fotográficos, permite-nos aventar uma série de hipóteses quanto ao contexto de produção:

a) teriam sido fotografados determinados eventos da Universidade para sua posterior divulgação junto à mídia externa;

b) as fotos poderiam ser produzidas para ilustrar as reportagens do boletim UnB Notícias, ou algum outro veículo interno de mídia;

c) as fotos teriam sido feitas simplesmente para um registro e arquivamento;

d) a realização das imagens pela Acs poderia ter ocorrido a pedido de outro órgão que não dispunha do instrumental necessário para o registro fotográfico. Nesse caso, segundo a teoria arquivística, tal órgão seria o produtor arquivístico.

Mas qual dessas hipóteses é a mais adequada? Para quais fotos? Que tipo de descrição se poderia fazer sem entender o contexto de produção daquela imagem? Das fotografias obtidas na pesquisa observamos que a descrição dos documentos foi feita apenas tomando por base seu conteúdo. Assim, 
FIGURA 2A

Fotografia $^{\circ} 1$ do Cedoc relativa ao DEG e respectiva ficha.

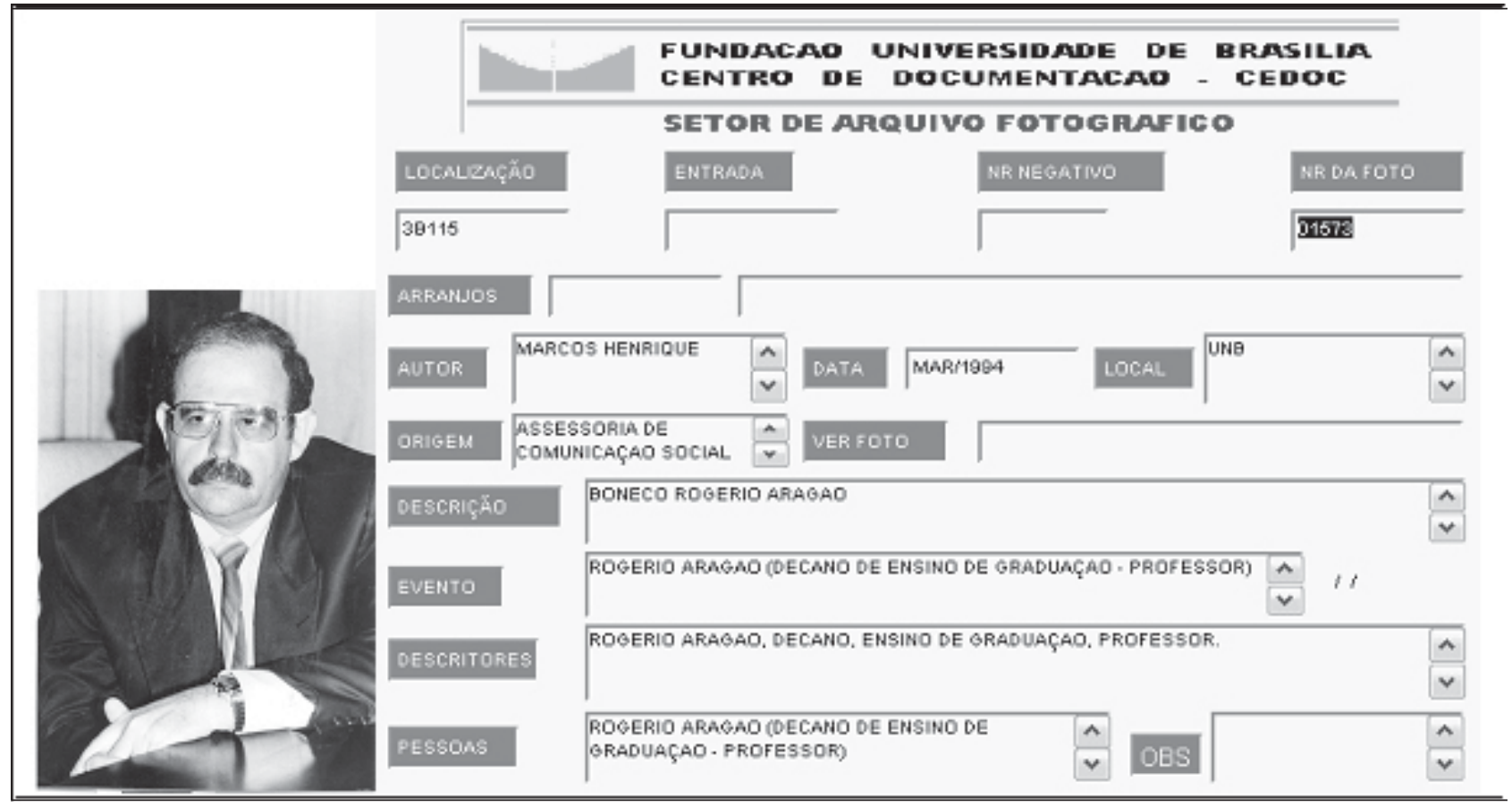

Fonte: Cedoc

FIGURA 3A

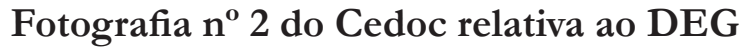

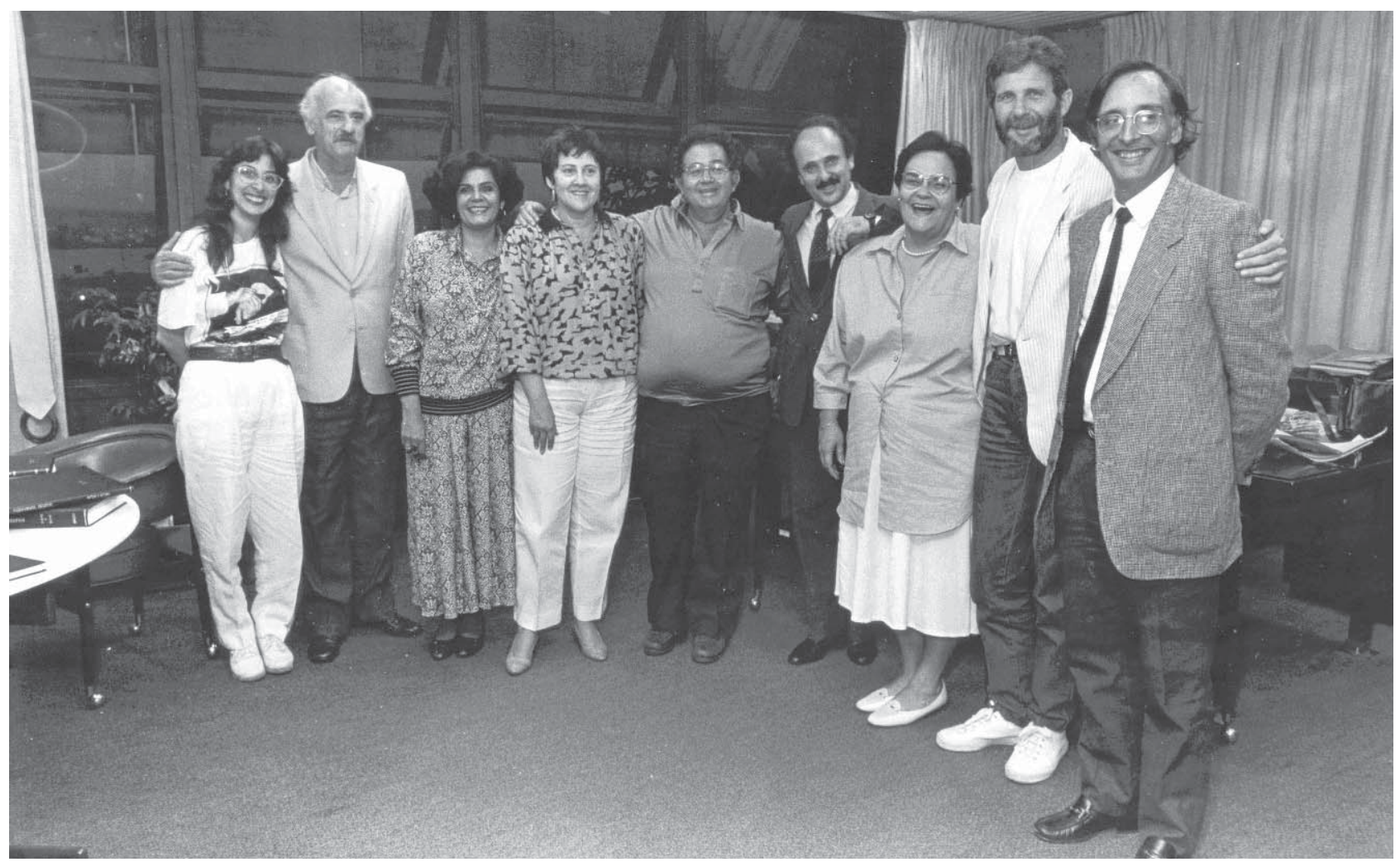

Fonte: Cedoc 
FIGURA 3B

Ficha da fotografia $n^{\circ} 2$

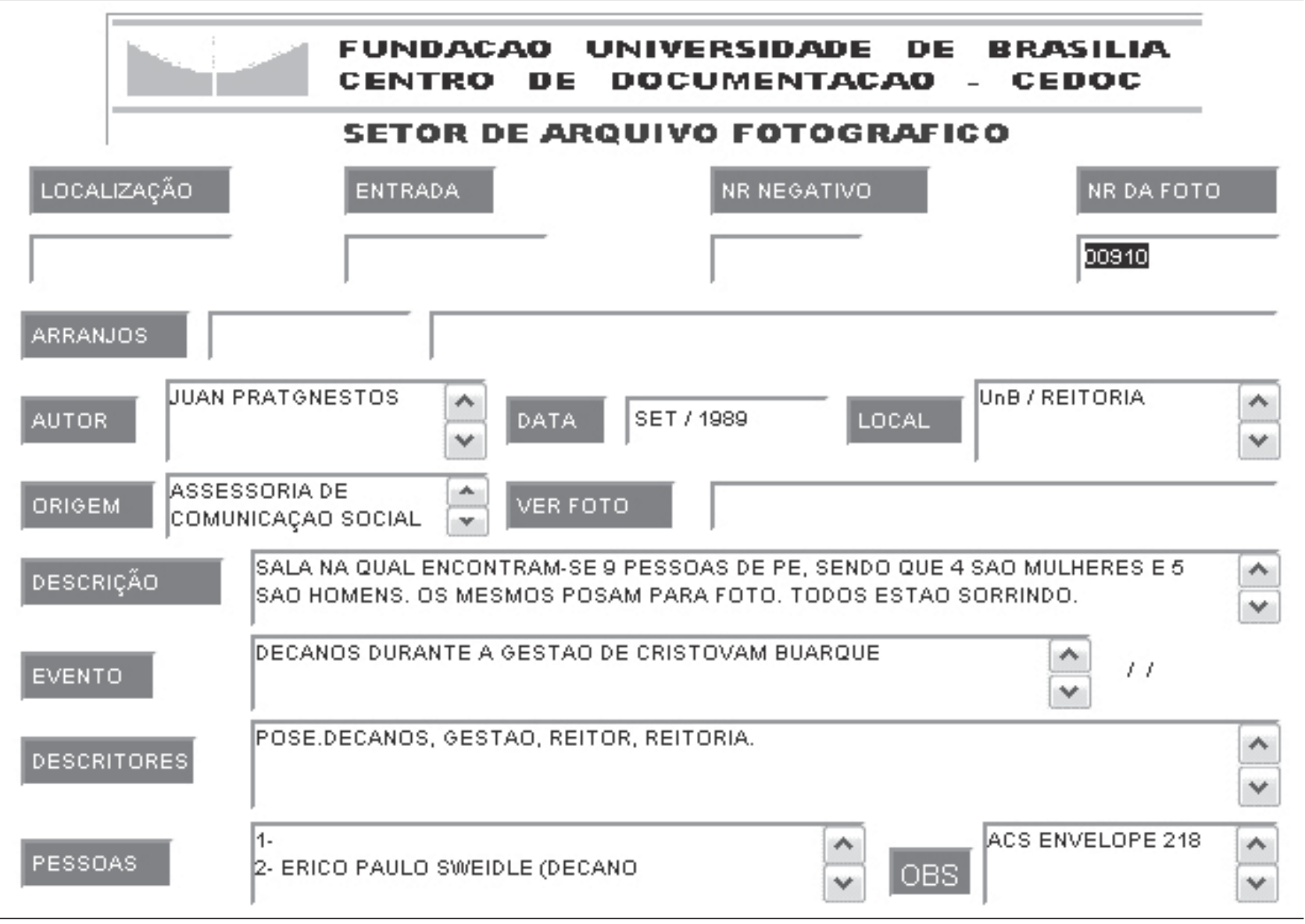

Fonte: Cedoc

FIGURA 3C

Detalhe do campo "pessoas" da ficha da fotografia no 2

1.

2. ERICO PAULO SWEIDLE (DECANO ADMINISTRAÇAO E FINANÇAS)

3.

4. PAULINA DE FREITAS (DECANA DE GRADUAÇAO - DEG)

5. ISAAC ROITMAN (DECANO DE PESQUISA E POS-GRADUAÇAO - DPP)

6. CRISTOVAM BUARQUE (REITOR)

7. EVA FALEIROS (DECANA DE ASSUNTOS COMUNITARIOS - DAC)

8. VOLNEI GARRAFA (DECANO DE EXTENSAO - DEX)

9. JOSE GERALDO DE SOUSA JUNIOR (CHEFE DE GABINETE)

Fonte: Cedoc 
FIGURA 4A

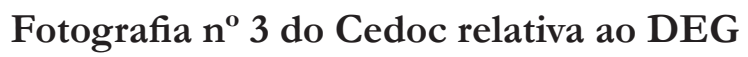

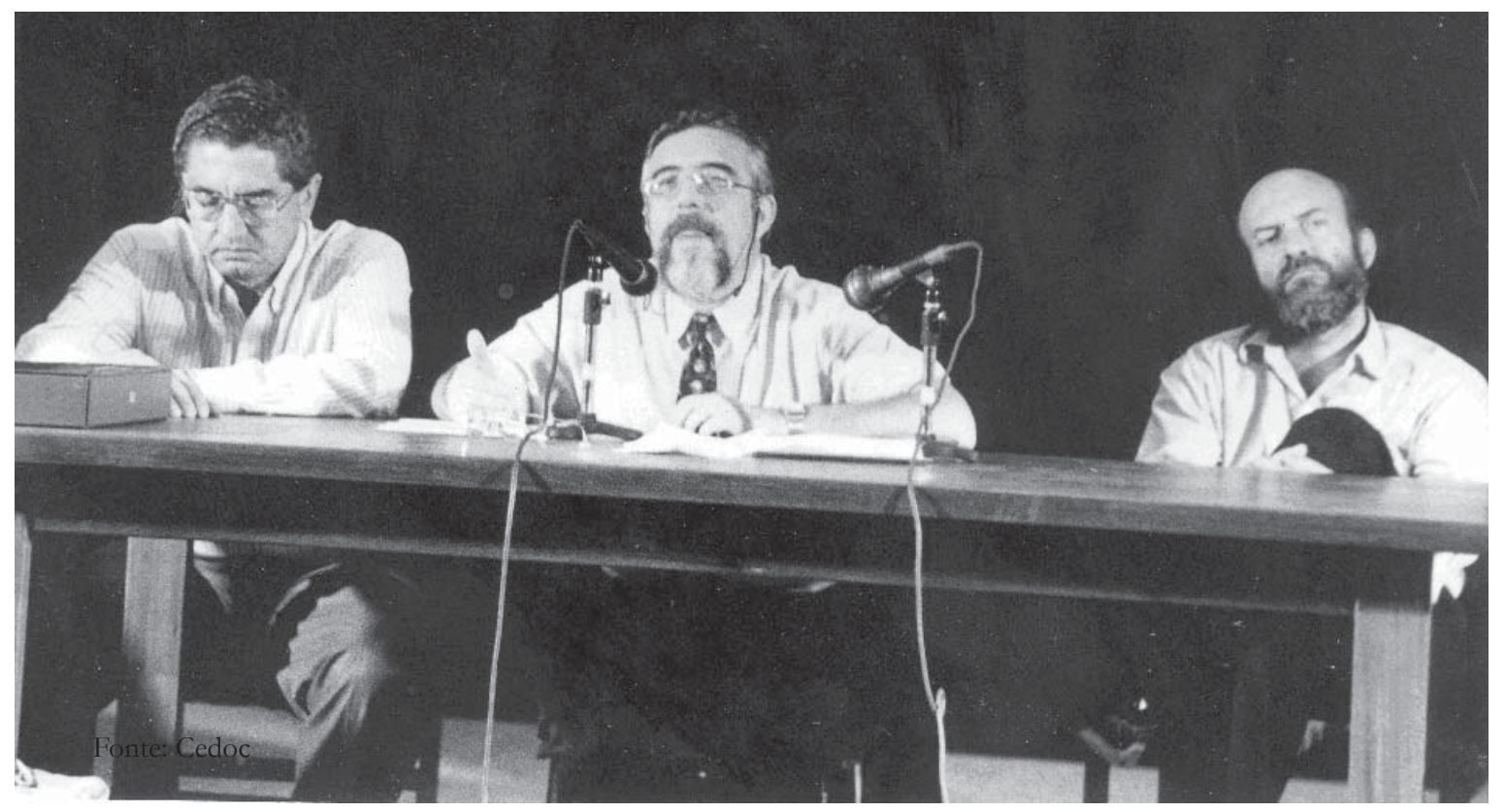

FIGURA 4B

Ficha da fotografia $n^{\circ} 3$

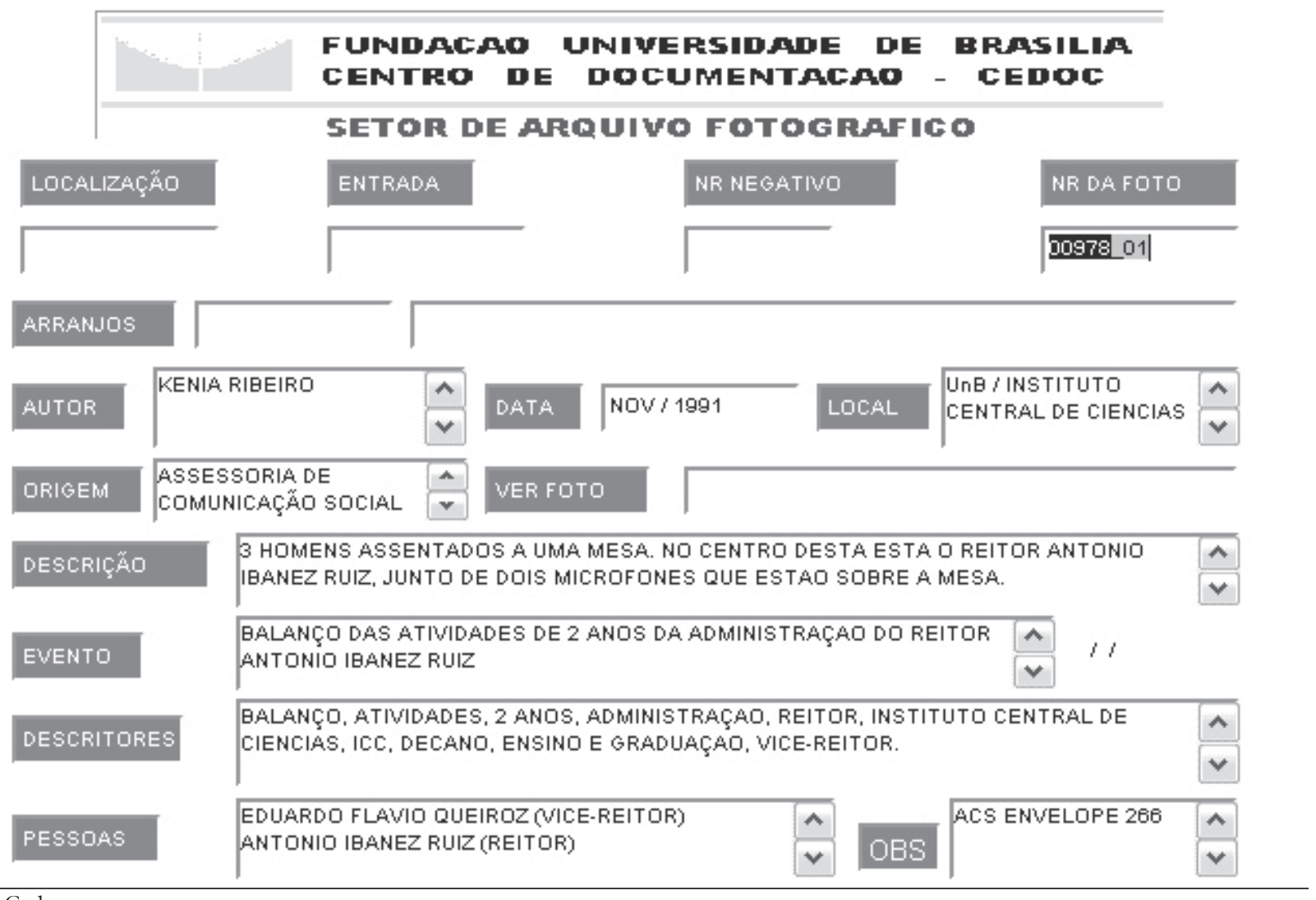

Fonte: Cedoc 
FIGURA 4C

Detalhe do campo "pessoas" da ficha da fotografia no 3

EDUARDO FLAVIO QUEIROZ (VICE-REITOR)

ANTONIO IBANEZ RUIZ (REITOR)

ANTONIO CARLOS PEDROÇA (DECANO DE ENSINO E GRADUAÇAO)

Fonte: CEDOC

FIGURA 5A

Fotografia n $^{\circ} 4$ do Cedoc relativa ao DEG

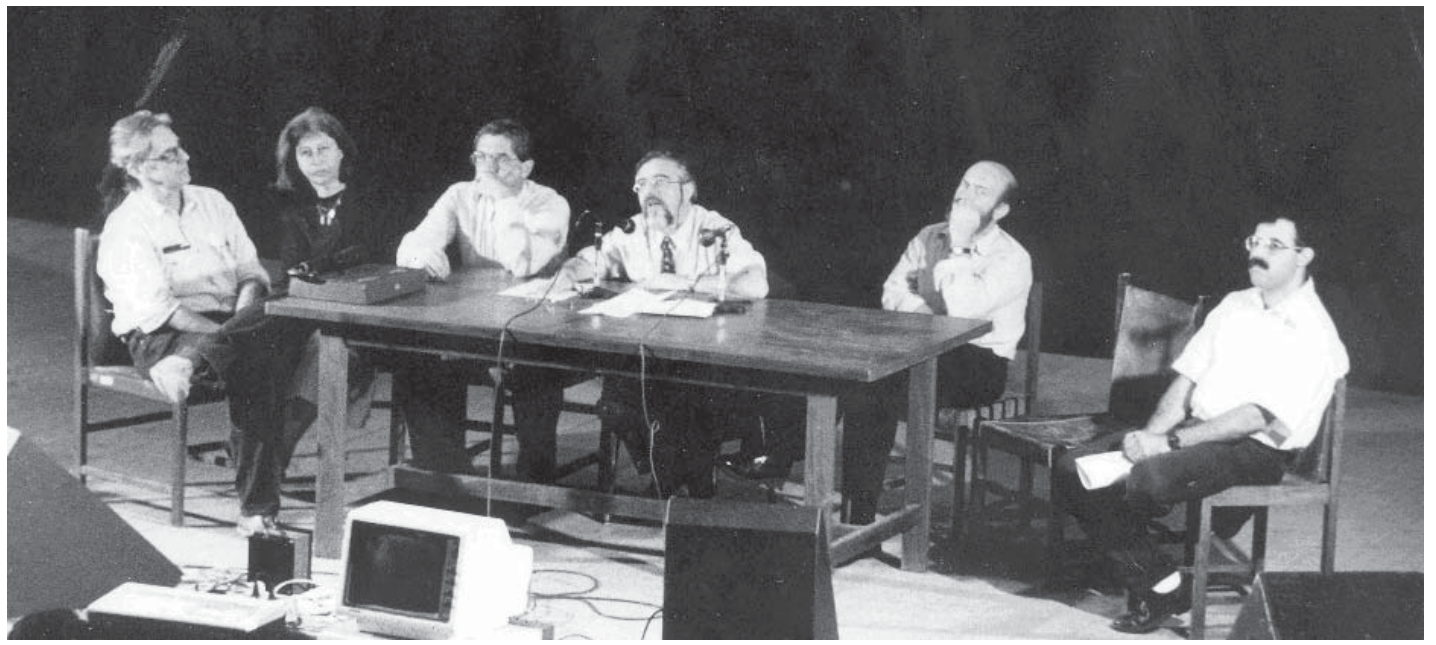

Fonte: Cedoc

FIGURA 5B

Ficha da fotografia $n^{\circ} 4$

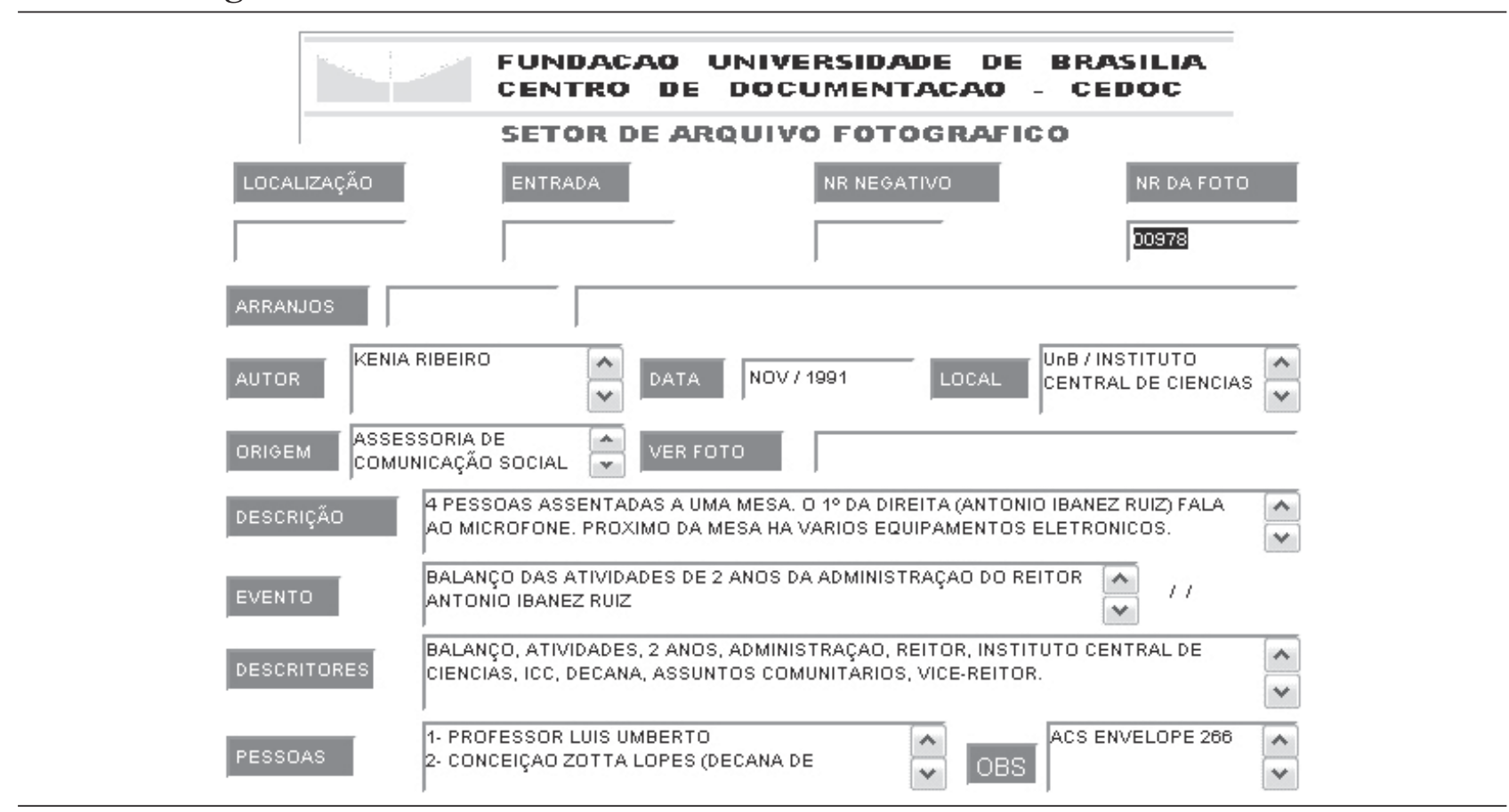

Fonte: Cedoc 
FIGURA 5C

Detalhe do campo "pessoas" da ficha da fotografia $n^{\circ} 4$

1. PROFESSOR LUIS UMBERTO

2. CONCEIÇAO ZOTTA LOPES (DECANA DE ASSUNTOS COMUNITARIOS)

3. EDUARDO FLAVIO QUEIROZ (VICE-REITOR)

4. ANTONIO IBANEZ RUIZ (REITOR)

FIGURA 6A

Fotografia $^{\circ} 5$ do Cedoc relativa ao DEG

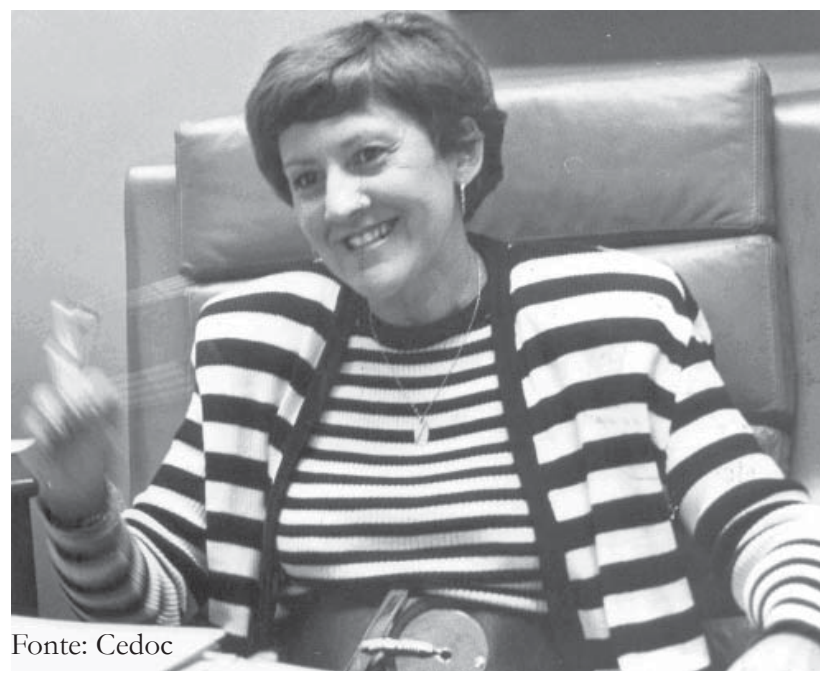

FIGURA 6B

Ficha da fotografia $n^{\circ} 5$

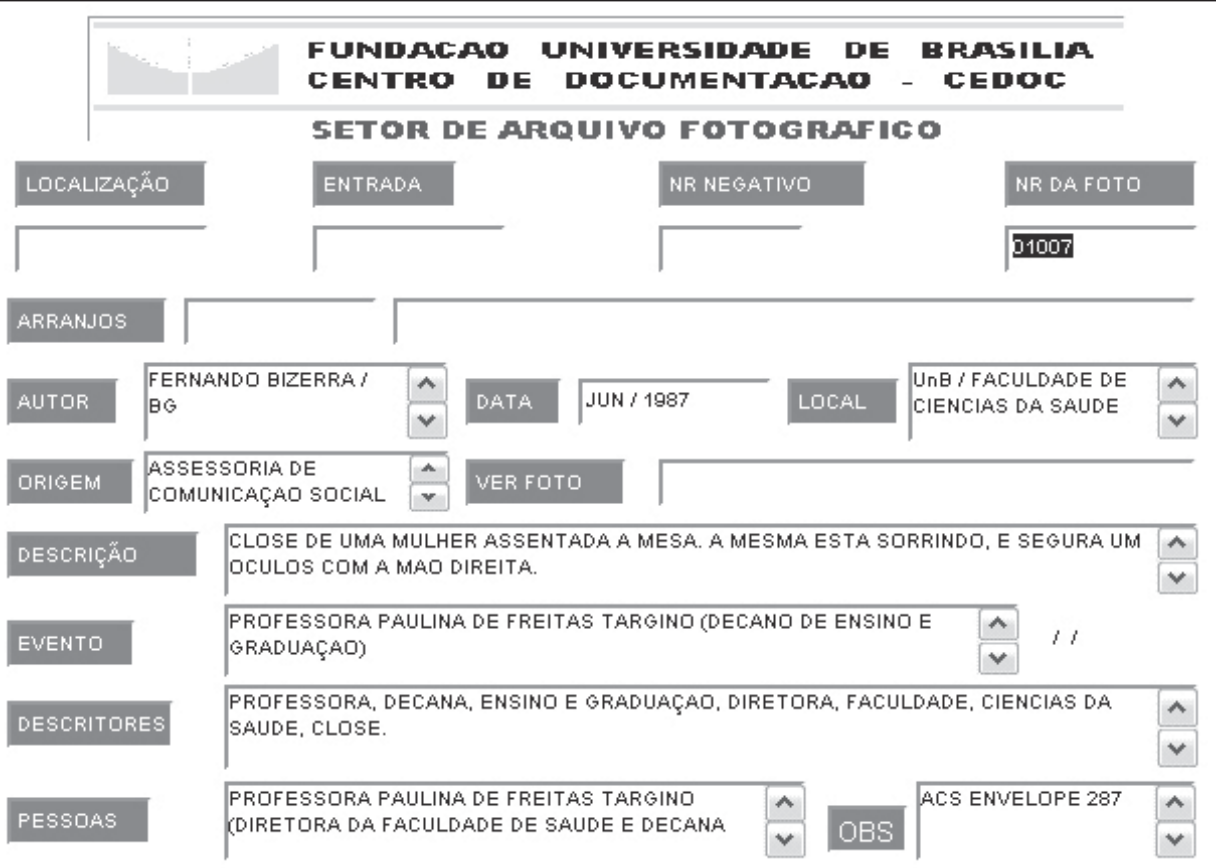

Fonte: Cedoc 
FIGURA 6C

Detalhe do campo "pessoas" da ficha da fotografia $n^{\circ} 5$

PROFESSORA PAULINA DE FREITAS TARGIINO (DIRETORA DA FACULDADE DE SAÚDE E DECANA DE ENSINO E GRADUAÇÃO)

Fonte: Cedoc

\section{FIGURA 7A}

\section{Fotografia $\mathrm{n}^{\circ} 6$ do Cedoc relativa ao DEG}

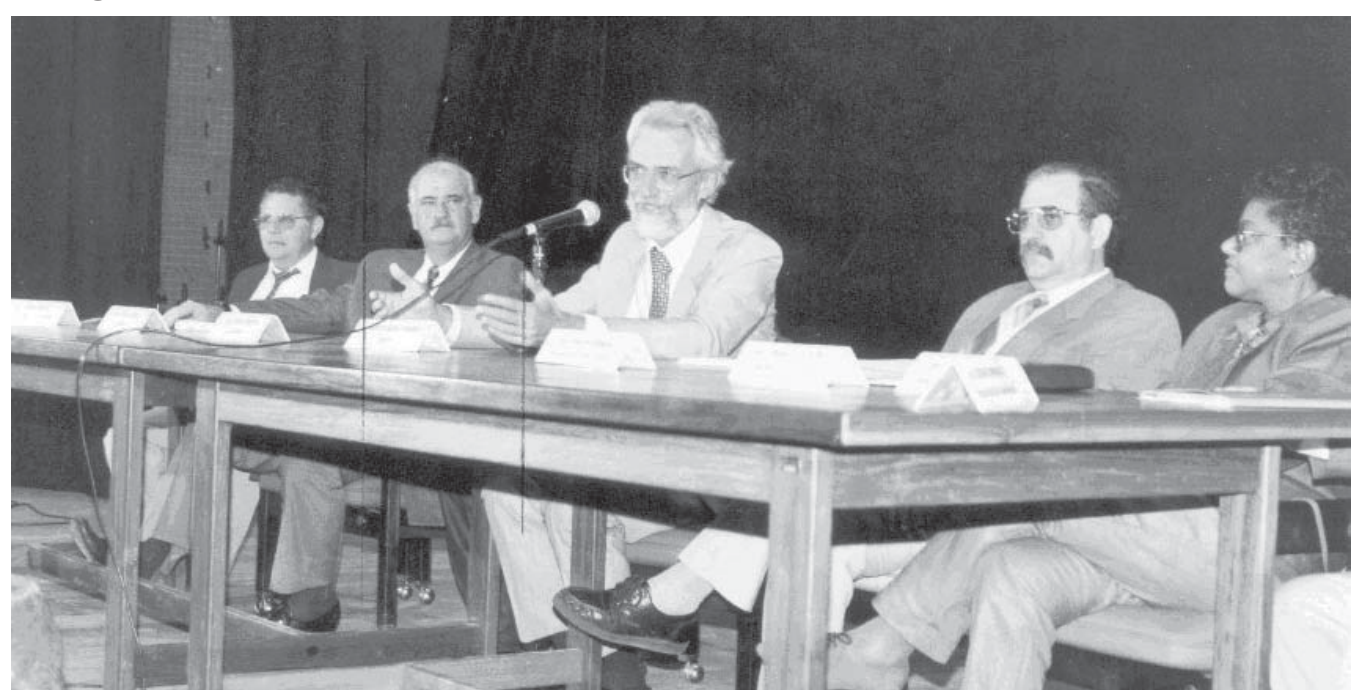

Fonte: Cedoc

FIGURA 7B

Ficha da fotografia $n^{\circ} 6$

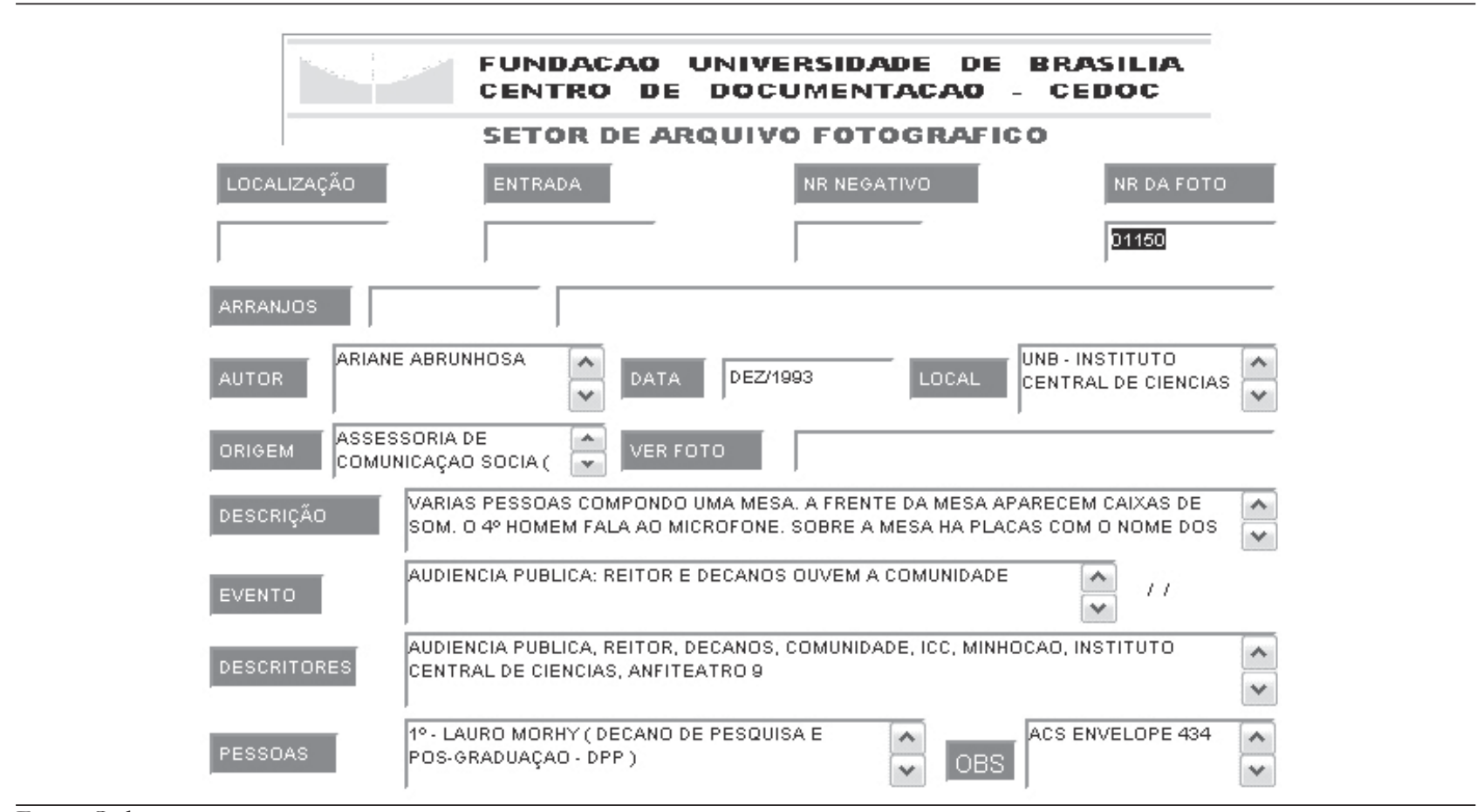

Fonte: Cedoc 
FIGURA 7C

Detalhe do campo "pessoas" da ficha da fotografia $n^{\circ} 6$

$1^{\circ}$ - LAURO MORHY (DECANO DE PESQUISA E POS-GRADUAÇAO - DPP )

$2^{\circ}$ - ERICO SEIGMAR WEIDLE ( VICE-REITOR)

$3^{\circ}$ - EDEIJAVA RODRIGUES LIRA (DECANO DE ASSUNTOS COMUNITARIOS - DAC)

$4^{\circ}$ - JOAO CLAUDIO TODOROV ( REITOR)

$5^{\circ}$ - FRANCISCO ROGERIO ARAÇAO (DECANO DE ENSINO DE GRADUAÇAO -DEG )

$6^{\circ}$ - MARIA JOSE DOS S. ROSSI ( DECANA DE EXTENSAO - DEX)

Fonte: Cedoc

FIGURA 8A

Fotografia $\mathrm{n}^{\circ} 7$ do Cedoc relativa ao DEG

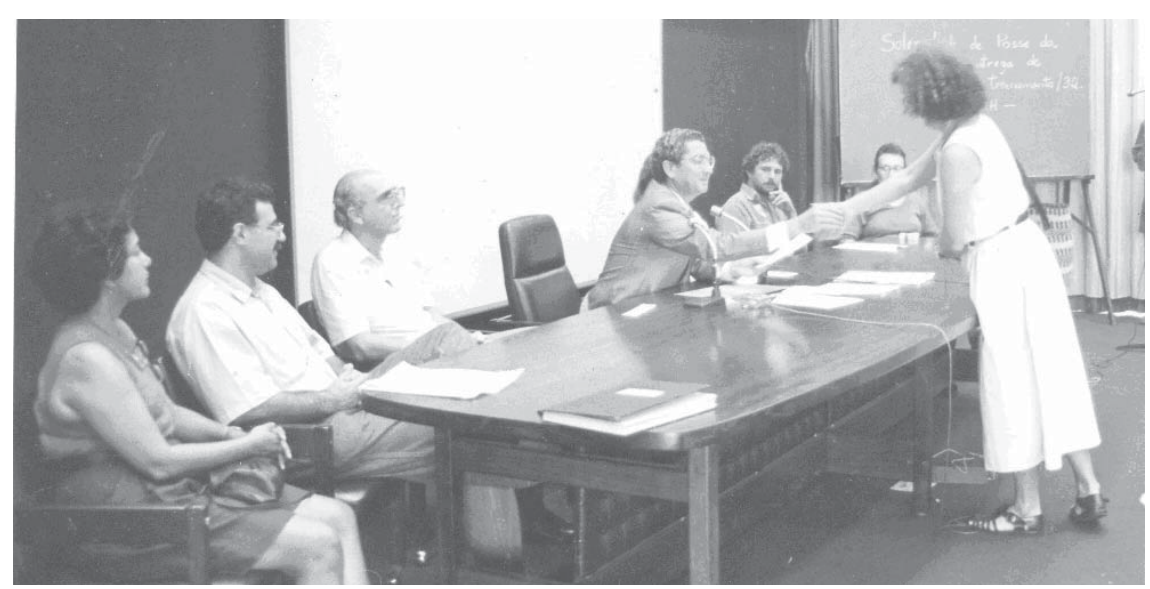

Fonte: Cedoc

FIGURA 8B

Ficha da fotografia $n^{\circ} 7$

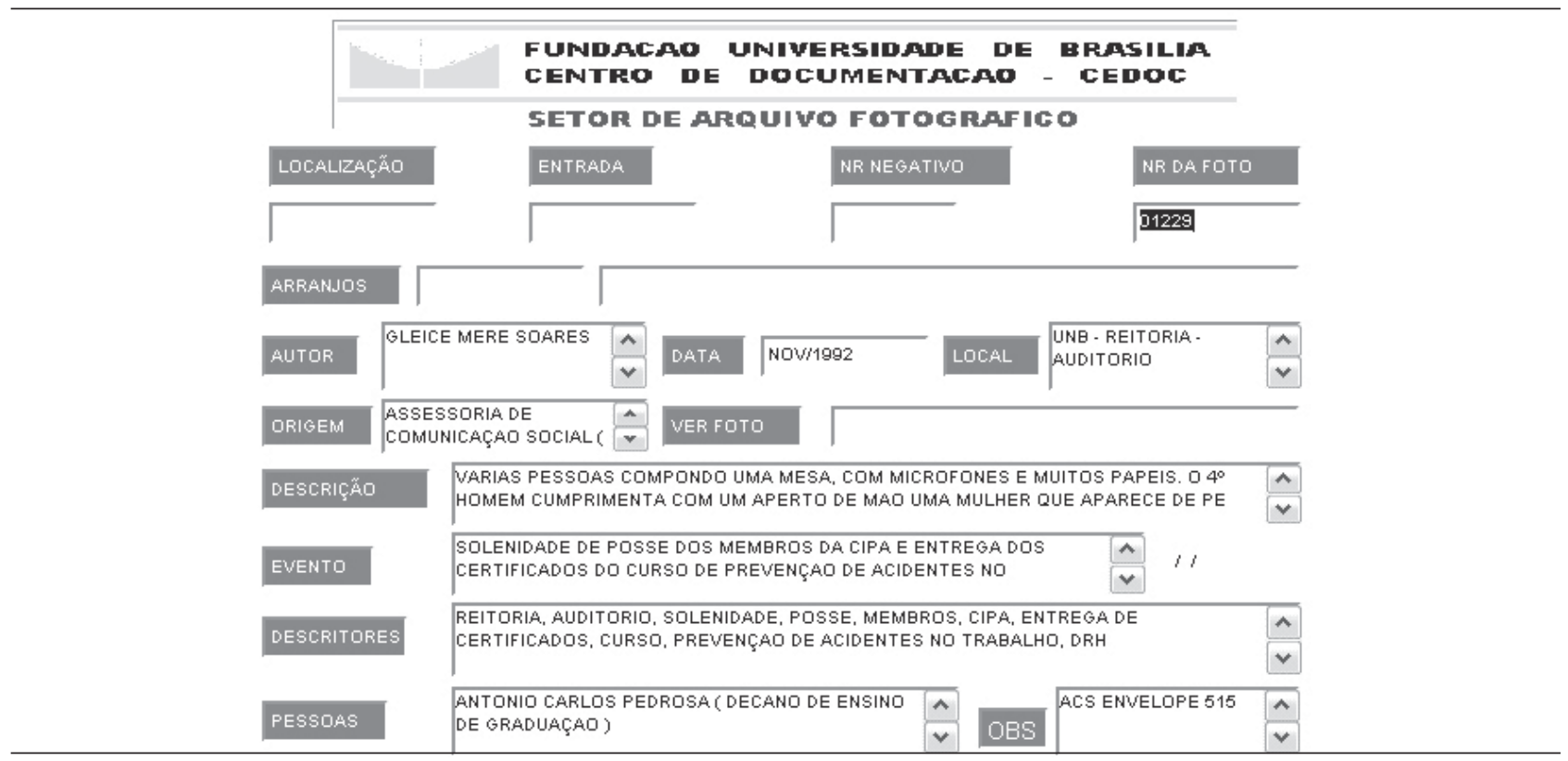

Fonte: Cedoc 
FIGURA 8C

Detalhe do campo "pessoas" da ficha da fotografia $n^{\circ} 7$

ANTONIO CARLOS PEDROSA ( DECANO DE ENSINO DE GRADUAÇAO )

ARMANDO BEZERRA ( DECANO DE ASSUNTOS COMUNITARIOS )

EDUARDO FLAVIO QUEIROZ ( VICE-REITOR)

Fonte: Cedoc

FIGURA 9A

Fotografia $^{\circ} 8$ do Cedoc relativa ao DEG

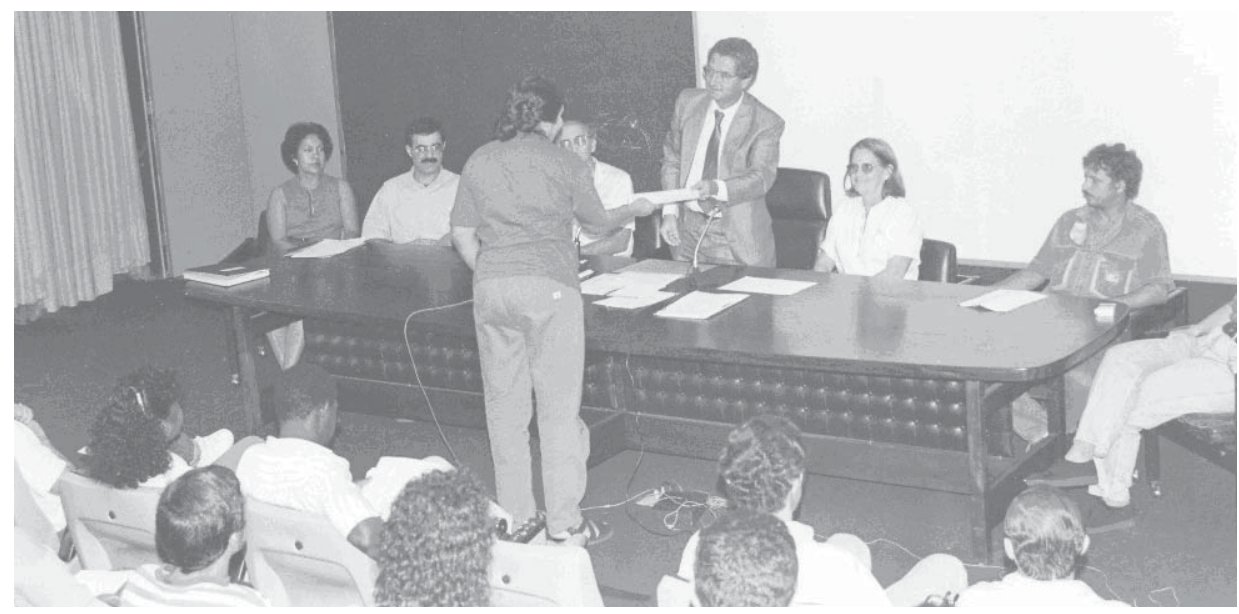

Fonte: Cedoc

FIGURA 9B

Ficha da fotografia $n^{\circ} 8$

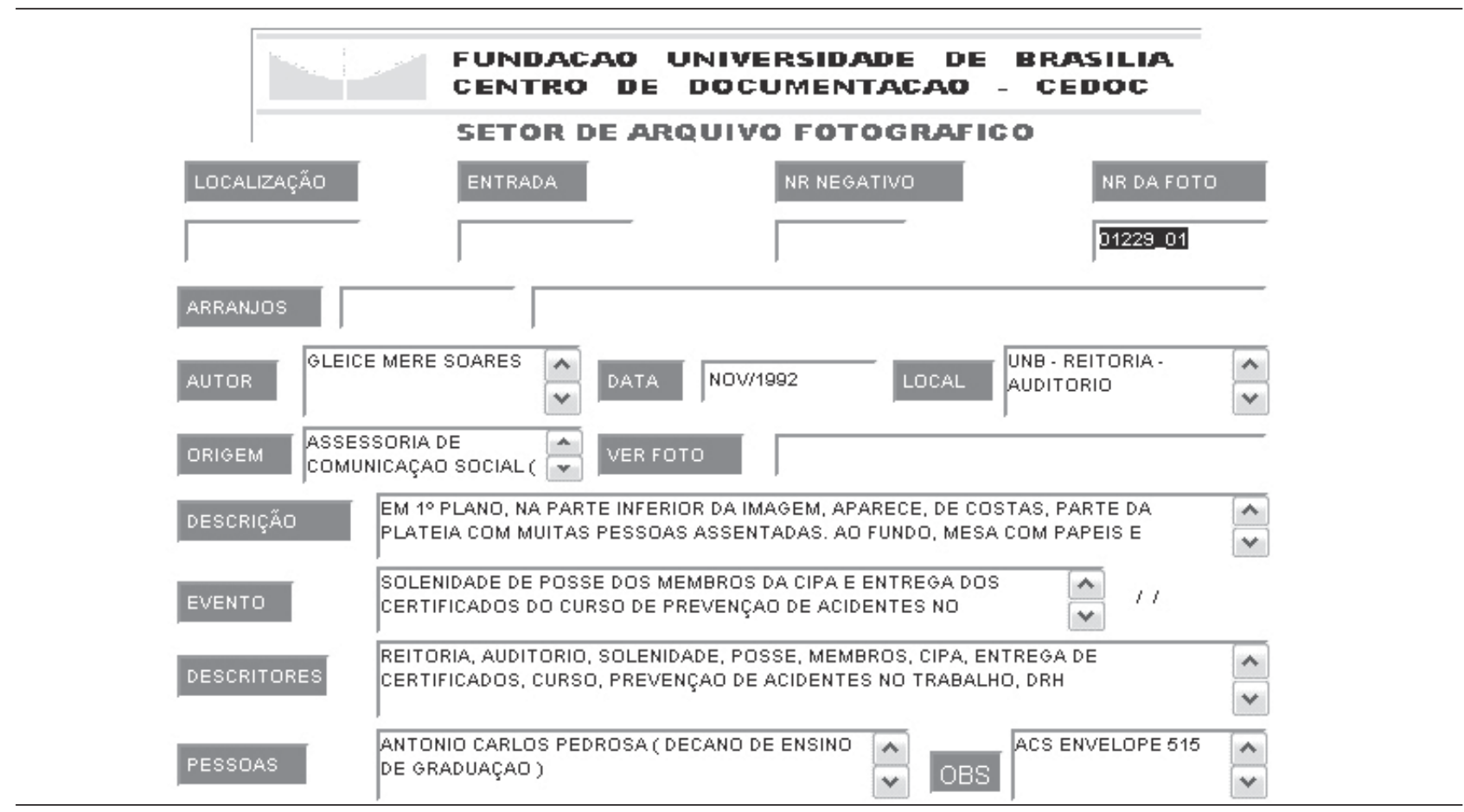

Fonte: Cedoc 
só podemos estudar os referidos documentos em função dos dados (poucos e nem sempre padronizados) das fichas de descrição. Nossa interpretação de tais imagens, como pode ser percebido adiante, é eivada de especulações e dúvidas. Um conhecimento anterior a respeito da produção das imagens - e do contexto administrativo dos eventos envolvidos, nos daria, sem dúvida, maiores subsídios para a compreensão do significado de cada documento. Entretanto, como foi observado, o instrumento de pesquisa disponibilizado deixa a desejar. A seguir indicamos, para cada foto, alguns aspectos de destaque.

A fotografia número um (1) não apresentou problemas com relação às palavras-chave, embora o campo local esteja bastante amplo uma vez que menciona apenas a palavra "UnB". Os demais campos tiveram seu preenchimento facilitado de certa forma por conta da identificação do fotografado, porém a finalidade da produção do documento e o ato administrativo que o originou permanecem sem nenhuma informação.

$\mathrm{Na}$ fotografia número dois (2), assim como em todas as outras, o campo descrição se limita pura e simplesmente ao que é exibido na fotografia com elementos completamente irrelevantes para a sua compreensão como o fato de as pessoas retratadas estarem sorrindo ou a quantidade exata de pessoas presentes. O campo evento não identifica nenhuma atividade específica e simplesmente informa, com grau de confiança questionável, que aquelas pessoas ocuparam cargos de decano durante a gestão de Cristovam Buarque. O campo local aponta a Reitoria, mas não explicita qual o local naquele edifício.

O uso da mesma palavra como descritor sugere que, numa busca de imagens referentes ao prédio da Reitoria, essa imagem em questão aparecerá junto a todas as outras que apresentem essa palavra como descritor, dificultando a recuperação da imagem desejada, no caso do edifício onde se encontram os órgãos centrais de administração da Universidade. Ainda sobre as palavras-chave, cabe destacar negativamente o uso do termo "pose", de finalidade incompreensível, e o nome de um dos decanos - Érico Weidle - grafado de modo incorreto, o que diminuiria as possibilidades de essa foto ser encontrada em uma eventual busca a imagens de tal pessoa.

As fotografias números três (3) e quatro (4) apresentam problemas similares a estes. $\mathrm{O}$ ambiente de apresentação da base de dados informa que a fotografia foi produzida pela Acs em um balanço de atividades de dois anos da administração do reitor Antonio Ibañez Ruiz. Essa informação, contudo, carece de complementos, tais como a espécie de reunião (se a reunião era geral, se era aberta à comunidade, ou tratava-se de reunião fechada apenas para os decanos e diretores das faculdades etc). Foi possível relatar o local da reunião (Instituto Central de Ciências, Icc) por conta de uma etiqueta colada no verso da foto que deu origem à imagem digitalizada, conforme dado aposto pelo emissor do documento. Seu uso como descritor, entretanto, redunda na recuperação dessa fotografia em uma eventual procura por fotografias do Icc.

A fotografia número cinco (5) é um retrato (em close) da ex-decana de ensino de graduação Paulina de Freitas Targino. Porém, no campo "pessoas", vemos, entre parênteses, o cargo de diretora da Faculdade de Saúde, o que permite questionar se ela acumulava os dois cargos, além de conferir dubiedade à informação. $O$ fato de ser um close permite inferir que essa imagem tenha sido utilizada para ilustrar alguma entrevista ou uma declaração feita ao jornal UnB Notícias produzido pela Acs, mas dificilmente, apenas com as informações apresentadas, conseguiremos ter a certeza do motivo que deu origem ao documento.

No campo evento da fotografia número seis (6), percebemos que o documento diz respeito a uma audiência pública, na qual o então reitor João Cláudio Todorov, acompanhado por decanos de sua gestão, ouviu o que a comunidade tinha a dizer. Há dois riscos vermelhos transversais na área onde é possível vislumbrar o rosto de um dos decanos, sugerindo algum procedimento técnico do fotógrafo para sua reprodução ou algum outro uso específico, que não são mencionados no campo observações.

Ci. Inf., Brasília, DF, v. 38, n. 3, p.160-176, set./dez., 2009 
Além disso, a adoção dos descritores "Anfiteatro 9", "Icc" e "Minhocão" pode acarretar os mesmos problemas de duplicidade de sentido já registrados nos comentários anteriores.

Nas fotografias sete (7) e oito (8), os campos evento e descritores apresentam a sigla CIPA, que não tem seu significado mencionado em nenhum momento. O uso de um glossário, ou do campo "obs", poderia indicar ao consulente menos avisado que se trata da Comissão Interna de Prevenção de Acidentes. A expressão "prevenção de acidentes no trabalho" é utilizada, embora a imagem descrita não trate especificamente do assunto. O tema, sem dúvida, está presente na gênese do documento, mas, como se pode perceber, as informações de ordem contextuais não foram consideradas.

As questões que apontamos mostram apenas alguns problemas oriundos da descrição de documentos de arquivo somente pelo conteúdo, sem recompor o contexto de produção e sem inserir os documentos em um plano de classificação capaz de dar conta das atividades efetivamente realizadas pelo produtor arquivístico. Cabe mencionar que a dificuldade da compreensão dos documentos tende a ser agravada com o passar do tempo, à medida que as informações, hoje implícitas, sobre os eventos e pessoas retratados, tornem-se cada vez mais difusas.

\section{CONCLUSÃO}

O Cedoc utiliza uma descrição detalhada dos conteúdos fotográficos, isolando os documentos do contexto em que foram criados. Em bancos de imagens essa prática não é diferente, visto que os mecanismos de recuperação atentam para o conteúdo informacional; o material arquivístico, porém demanda outro tipo de informação. Nas fichas das fotografias que fazem menção ao Deg reproduzidas no artigo, fica evidente a ausência de dados contextuais mínimos, não permitindo a identificação dos elementos básicos da organicidade arquivística: a proveniência (titularidade) e a atividade administrativa geradora do documento. Ainda foi detectada a falta de instrumentos de pesquisa (guias, inventários e catálogos) no Cedoc, denotando a ausência de uma política institucional de descrição arquivística. As recomendações das normas que atualmente regem a descrição arquivística, tanto em nível internacional como nacional - a Isad-g e a Nobrade -, tampouco são consideradas.

A pesquisa entendeu que o sistema utilizado pelo Cedoc para o tratamento das fotografias é ineficiente quanto à recuperação das informações arquivísticas e, por conseguinte, dos respectivos documentos. Recomenda-se que o setor, em um primeiro momento, passe a incorporar, nas informações individualizadas de cada fotografia, dados referentes à organicidade arquivística dos documentos, para o que será necessário efetuar a classificação arquivística do acervo.

Posteriormente, seria igualmente recomendável o estabelecimento de uma ferramenta de gestão para todo o acervo, com vistas a garantir a integridade da informação arquivística dos atuais documentos e dos que serão incorporados futuramente. Tal ferramenta, somada aos dados de organicidade e ao atual excelente trabalho de conservação física, permitiria o estabelecimento de uma adequada política de descrição institucional. Esta última deverá ser executada segundo as recomendações das normas internacionais e nacionais vigentes. Com tais atitudes, o Cedoc finalmente passaria a estar em conformidade com os procedimentos apregoados pelo Conselho Internacional de Arquivos e pelo Conselho Nacional de Arquivos*.

\footnotetext{
* Em importante evento internacional, reafirmou-se a importância da permanência dos dados de contexto arquivístico no tratamento de materiais fotográficos. Ver Lopez (2009), Malešič e Štolfa (2009) e Šuligoj (2009).
}

Artigo submetido em 23/02/2009 e aceito em 17/11/2009. 


\section{REFERÊNCIAS}

BELLOTTO, Heloísa L. Arquivos permanentes: tratamento documental. 2. ed. Rio de Janeiro: FGV, 2004.

BRASIL. Conselho Nacional de Arquivos. Nobrade: norma brasileira de descrição arquivística. Rio de Janeiro: Arquivo Nacional, 2006. Disponível em: < http://www. portalan.arquivonacional.gov.br/ Media/nobrade.pdf>. Acesso em: 1 jun. 2007.

CORNELSEN, Julce M.; NELLI, Victor J. Gestão integrada da informação arquivística: o diagnóstico de arquivos. Arquivistica.net, Rio de Janeiro, v. 2, n. 2, p. 70-84, ago./dez. 2006.

DICIONÁRIO de terminologia arquivística. São Paulo: AAB-Sp; Secretaria de Estado da Cultura, 1996.

EVANS, Frank B.; KETELAAR, Eric. Guia para la encuesta sobre los sistemas y servicios de la gestión de documentos y la administración de archivos: un estudio del RAMP. Paris: UNEsco, 1983.

GOMBRICH, Ernst H. La imagen y el ojo: nuevos estudios sobre la psicología de la representación pictórica. Madrid: Debate, 2000.

INTERNATIONAL COUNCIL ON ARCHIVES. Isad (g): general international standard archival description. 2. ed. Ottawa, 2000.

JOLY, Martine. Introdução à análise da imagem. Campinas: Papirus, 1996.

LOPEZ, André P. A. Alcance da descrição arquivística e o processo de automação. Registro: revista do Arquivo Público Municipal de Indaiatuba. Indaiatuba, n. 2, p. 27-39, 2003 b.

Arquivos pessoais e as fronteiras da arquivologia. Gragoatá: Revista do Programa de Pós-Graduação em Letras (UFF), Niterói, n. 15 , p. $69-82,2^{\circ}$ semestre, 2003 a.

La clasificación archivística como actividad previa para la descripción de documentos imagéticos. In: AGUAYO, Fernando; RoccA, Lourdes (Orgs.). Imágens e investigación social. Mexico, Instituto Mora, 2005. (Historia social y cultural).

Como descrever documentos de arquivo: elaboração de instrumentos de pesquisa. São Paulo: AESP/IMESP, 2002b. (Projeto Como Fazer, 6). Disponível em: <http://www.arquivoestado.sp.gov.br/saesp/ texto_pdf_15_Como $\% 20$ descrever $\% 20$ documentos $\% 20 \mathrm{de} \% 20$ arquivo_elaboracao $\% 20 \mathrm{de} \% 20$ instrumentos $\% 20 \mathrm{de} \% 20$ pesquisa. pdf.> Acesso em: 12 set. 2009.

El contexto archivístico como directriz para la gestión documental de materiales fotográficos de archivo. Universum. Talca, v. 23, n. 2, p. 12-37, 2008. Disponível em: <http://www. scielo.cl/scielo.php? script $=$ sci_arttext\&pid $=$ S0718-237620 $08000200002 \& \operatorname{lng}=$ es\&nrm=iso $>$. Acesso em: 12 set. 2009.
International Standard Archival Description: observações sobre a ISAD-g. Revista Histórica: revista do Arquivo do Estado de São Paulo, São Paulo, n. 7, p. 38-46, jun./ago. 2002a.

Photographic document as image archival document. In: TEHNIČNI IN VSEBINSKI PROBLEMI KLASIČNEGA IN ELEKTRONSKEGA ARHIVIRANJA: referatov dopolnilnega izobraževanja s področij arhivistike, dokumentalistike in informatike v Radencih, 8, Maribor, 2009. Tebnićni in V sebinski Problemi ... Maribor: Pokrajinski Arhiv Maribor, 2009. p. 362-272. Disponível em: < http:/ / eprints.rclis.org/15796/>. Acesso em: 12 set. 2009.

As razões e os sentidos: finalidades da produção documental e interpretação de conteúdos na organização arquivística de documentos imagéticos. 2000. Tese (Doutorado em História Social). Programa de Pós-Graduação em História Social da FFLCH-USP. São Paulo: 2000. Disponível em: < http:/ / eprints.rclis.org/15797/>. Acesso em: 12 set. 2009.

MALEŠIČ, Jasna; ŠTOLFA, Andrej. Zaščita najstarejšega fotografskega gradiva $\mathrm{v}$ Narodni in Univerzitetni Knjižnici. In: TEHNIČNI IN VSEBINSKI PROBLEMI KLASIČNEGA IN ELEKTRONSKEGA ARHIVIRANJA: referatov dopolnilnega izobraževanja s področij arhivistike, dokumentalistike in informatike v Radencih, 8, Maribor, 2009. Tebnićni in V sebinski Problemi ... Maribor: Pokrajinski Arhiv Maribor, 2009. p. 335-342.

PAES, Marilena L. Arquivo: teoria e prática. 3. ed. Rio de Janeiro: FGV, 2004.

PARINET, Elisabeth. Diplomatics and institucional photos. The American Archivist: The Society of American Archivists, Chicago, n. 59, p. 480-485, fall 1996.

SMIT, Johanna W. A função da fotografia e a identificação do conteúdo da imagem fotográfica. In: Congresso Brasileiro de Arquivologia, 10, São Paulo, 1994. Anais ... São Paulo: AAB, 1998. (Cd-rom).

- A representação da imagem. Informare: cadernos do Programa de Pós-graduação em Ciência da Informação, Rio de Janeiro, n. 2, p. 28-36, jul./dez. 1996.

ŠULIGOJ, Tatjana R. Fotoreprodukcije arhitekturnih in drugih načrtov: prepoznavaje in varovanje. In: TEHNIČNI IN VSEBINSKI PROBLEMI KLASIČNEGA IN ELEKTRONSKEGA ARHIVIRANJA: referatov dopolnilnega izobraževanja spodročij arhivistike, dokum entalistike in informatike v Radencih, 8, Maribor, 2009. Tebnicni in V sebinski Problemi ... Maribor: Pokrajinski Arhiv Maribor, 2009. p. 347-356. 